UCRL-ID-126458

\title{
Crystal Growth of Optical Materials for Advanced Lasers
}

K. I. Schaffers

S. A. Payne

February 4, 1997

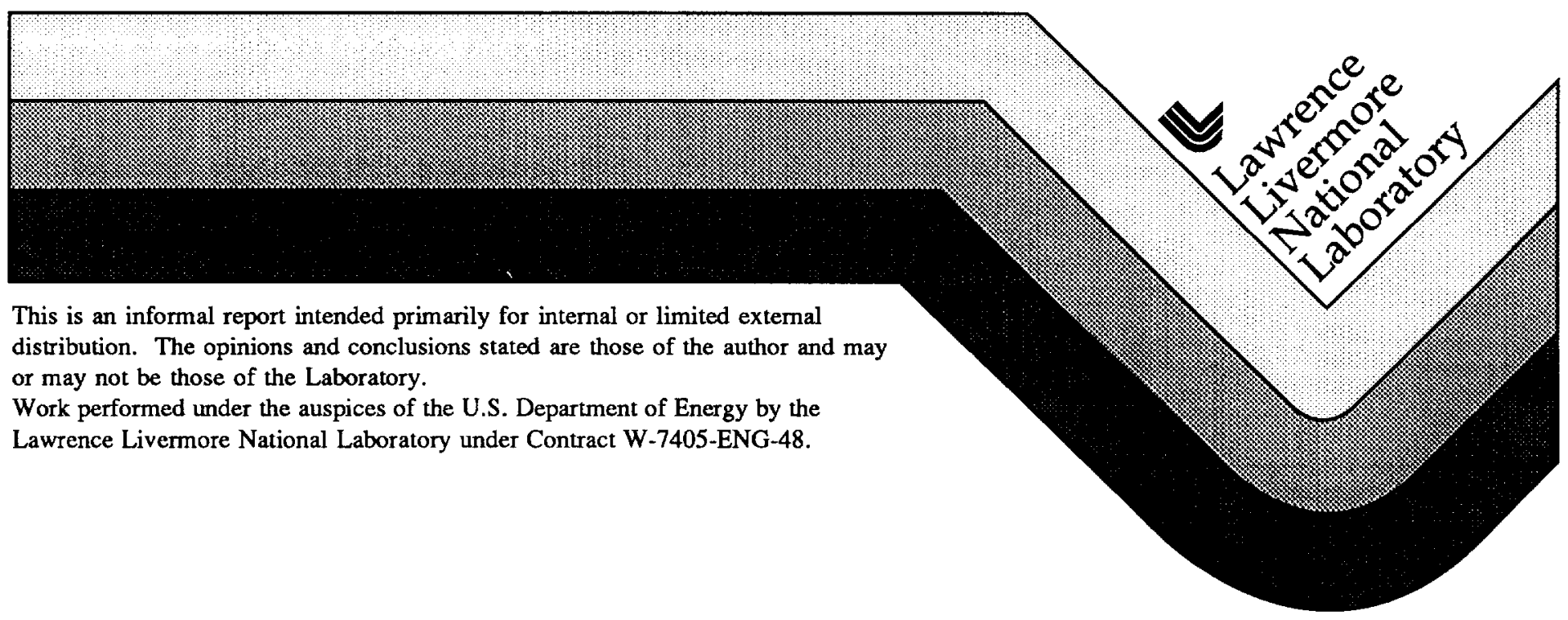




\section{DISCLAIMER}

This document was prepared as an account of work sponsored by an agency of the United States Government. Neither the United States Government nor the University of California nor any of their employees, makes any warranty, express or implied, or assumes any legal liability or responsibility for the accuracy, completeness, or usefulness of any information, apparatus, product, or process disclosed, or represents that its use would not infringe privately owned rights. Reference herein to any specific commercial product, process, or service by trade name, trademark, manufacturer, or otherwise, does not necessarily constitute or imply its endorsement, recommendation, or favoring by the United States Government or the University of California. The views and opinions of authors expressed herein do not necessarily state or reflect those of the United States Government or the University of California, and shall not be used for advertising or product endorsement purposes.

This report has been reproduced directly from the best available copy.

Available to DOE and DOE contractors from the Office of Scientific and Technical Information

P.O. Box 62, Oak Ridge, TN 37831

Prices available from (615) 576-8401, FTS 626-8401

Available to the public from the

National Technical Information Service

U.S. Department of Commerce

5285 Port Royal Rd.,

Springfield, VA 22161 


\section{Crystal Growth of Optical Materials for Advanced Lasers Kathleen I. Schaffers and Stephen A. Payne tracking code: 96-ERD-039}

During FY96, two specific projects have been addressed, Yb-doped fluoroapatite (Yb:SFAP) and Cr:ZnSe crystals, which are being used as the gain media to develop diode-pumped solid-state lasers (DPSSL). Both materials have unique properties for near infrared to midinfrared applications. However, as with most new materials, there are defects in the crystals that create optical losses and reduce the efficiency of the lasers. Therefore, the source of the losses in the crystals has been studied and techniques have been developed to reduce and/or eliminate defects to aid in the growth of high optical quality crystals to increase laser efficiency.

\section{$Y b: S-F A P\left[\mathrm{Yb}^{3+}: \mathrm{Sr}_{5}\left(\mathrm{PO}_{4}\right)_{3} \mathrm{~F}\right]$}

$\mathrm{Yb}: \mathrm{S}$-FAP and its derivatives have been targeted as candidates for use as diode-pumped solid-state lasers (DPSSL) for high average power applications. Specifically, these crystals have been chosen as the gain media for the development of the Mercury Laser which is a gas-cooledslab (GCS) DPSSL. ${ }^{1}$ The scope of this project was to produce high-quality crystals for initial testing and for future implementation in laser systems. $\mathrm{Yb}^{3+}$-based lasers have only recently been studied in the laser community, therefore, the Yb:S-FAP crystals are not yet commercially available and had to be grown and studied at LLNL.

Crystals of Yb:S-FAP are grown by the Czochralski method where a crystalline Yb:SFAP seed is inserted into a molten mixture of the material components for growth. At the appropriate temperature and gradients, crystallization onto the seed will begin and a crystal is then slowly pulled from the melt at approximately $1 \mathrm{~mm} / \mathrm{hr}$ while rotating at $20 \mathrm{rpm}$. Typical boule sizes are up to 1 inch in diameter by 7" in length.

Two distint defects can be present in as-grown boules of Yb:S-FAP: cloudiness from precipitation of starting components at the growth interface and core-type defects. During FY96 we developed a high-temperature post-growth annealing process that has been successful in alleviating the cloudiness that appears in as-grown boules. In this process, the crystal is suspended over the melt surface for up to 7 days in a temperature zone of the growth furnace that is $\sim 300^{\circ} \mathrm{C}$ below the melting point. By using this technique, it has been possible to produce crystals with $<0.1 \% / \mathrm{cm}$ optical scattering losses and $<\sim 1 \% / \mathrm{cm}$ impurity absorption losses at the emission wavelength $(1047 \mathrm{~nm})$ of the laser. While these specifications are adequate for efficient laser operation, additional improvements may be possible.

To further study and understand the source of the defects, a series of experiments have been performed to anneal away the cloudiness in alternative atmospheres, including $\mathrm{SrF}_{2}$, inert (argon), and slightly oxygen rich; all have proven inadequate. The cloudiness worsened for the $\mathrm{SrF}_{2}$ and oxygen rich cases and there was only a slight improvement in the argon atmosphere. One explanation for these results is that some component of the Yb:S-FAP melt is diffusing into the boules. However, it has been shown that the temperature for annealing is likely the most important parameter. Core defects are another issue that must be addressed to make more efficient use of the boules that are grown. These defects manifest themselves as "hair-like" streamers, about $1-10 \mathrm{~mm}$ in length, that begin at approximately $4-5 \mathrm{~cm}$ down the boule, and spread out in a "pyramid" formation down the length of the boule (Figure 1). In addition, the number of defects appear to increase with $\mathrm{Yb}$ concentration in the melt. This statement is supported by Scanning Electron Microscopy (SEM) X- 
ray analysis of a core defect where the dominant component was measured to be Yb-based, likely $\mathrm{Yb}_{2} \mathrm{O}_{3}$ or $\mathrm{YbOF}$. Experimental data suggests that there is a stoichiometry problem that develops in the melt over time as the crystal is growing. The improvements realized by adding excess $\mathrm{SrF}_{2}$ to the starting melt composition imply that the vaporization of $\mathrm{SrF}_{2}$ at $1810^{\circ} \mathrm{C}$ from the melt surface creates an imbalance in composition and therefore the left over components precipitate out of the melt as core defects to maintain the correct stoichiometry. This important conclusion, based on the FY 96 work, has significantly improved the potential for reducing and/or eliminating these defects in Yb:S-FAP crystals.

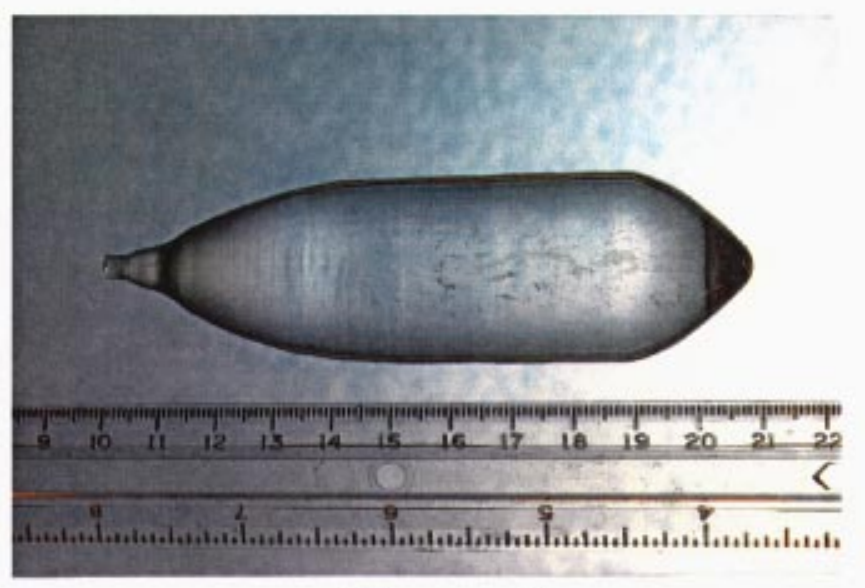

Figure 1

High-quality crystals of La-doped S-FAP have also been grown for use as end caps for $\mathrm{Yb}$ :S-FAP crystals used in a study for the Laser Isotope Separation (LIS) program to predict the potential of replacing the copper vapor lasers with a DPSSL. These end caps eliminated problems with cracking from thermal stresses in the laser rods and allowed the success and completion of this phase of the project.

In addition, for many applications, the absorption band [full width at half maximum $(\mathrm{FWHM}) \cong 5 \mathrm{~nm}]$ of $\mathrm{Yb}: \mathrm{S}$-FAP is too narrow for ideal pumping efficiency at $900 \mathrm{~nm}$ when using large, low-cost diode arrays (FWHM $\cong 6-8$ ). This nonideal overlap only utilizes approximately $75 \%$ of the available pump power which increases the number and cost of the diodes required for the laser designs. Therefore, we attempted to broaden the absorption band of the $\mathrm{Yb}$ crystals to better accommodate the performance of the diode arrays while simultaneously maintaining all other favorable laser and materials properties for efficient operation at high peak power. To accomplish these goals, crystals of $\mathrm{Yb}: \mathrm{Sr}_{5-\mathrm{x}} \mathrm{Ba}_{\mathrm{x}}\left(\mathrm{PO}_{4}\right)_{3} \mathrm{~F}$ were grown where $0 \leq \mathrm{x} \leq 5{ }^{2}$ Spectroscopic analysis of these mixed crystals shows that with increasing $\mathrm{Ba}$ in the $\mathrm{Yb}: \mathrm{S}$-FAP lattice, the absorption linewidth broadens from $5 \mathrm{~nm}$ for $\mathrm{x}=0$ to $13-15 \mathrm{~nm}$ for $\mathrm{x}=1$ and 2 , with a continuous increase for intermediate concentrations (Figure 2a). This increase is more suitable for diode pumped lasers. The emission spectra were also studied to predict the effect of $\mathrm{Ba}$ on the ability to extract energy from the gain media. What we see is that for Ba concentrations from $x=0$ to $x=2$, there tends to be a continual decrease in emission cross-section or intensity by only about a factor of two (Figure $2 \mathrm{~b}$ ). These intial results predict that the $\mathrm{Yb}: \mathrm{Sr}_{5}$ ${ }_{x} \mathrm{Ba}_{\mathrm{x}}\left(\mathrm{PO}_{4}\right)_{3} \mathrm{~F}$ crystals will offer the laser designer the ability to essentially "dial in" the properties required for different laser systems by modifying the Ba concentration. 


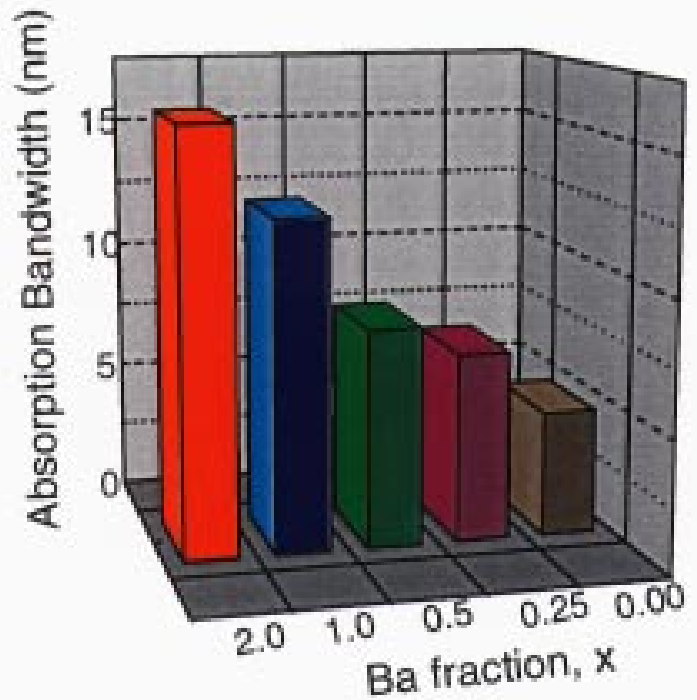

Figure 2a

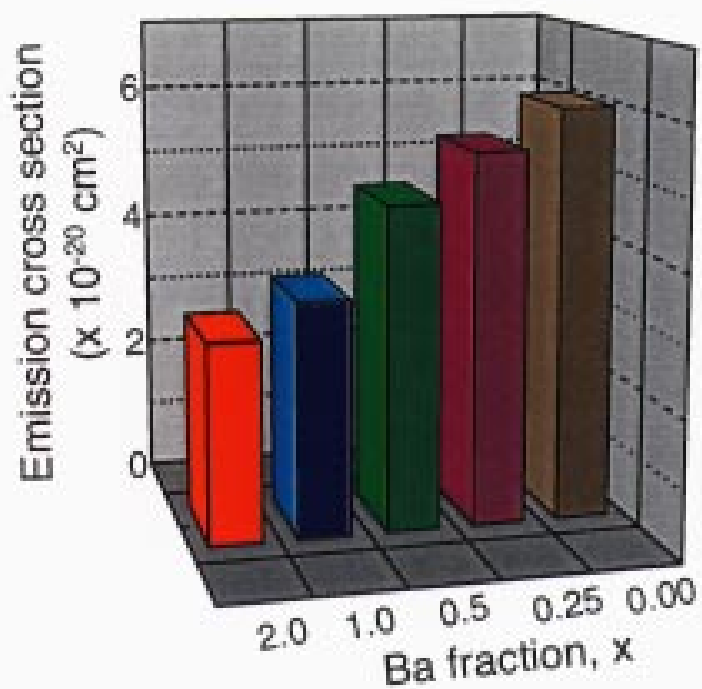

Figure 2b

\section{$\mathrm{Cr}^{2+}: \mathrm{ZnSe}$}

The second phase of the FY96 work was centered around $\mathrm{Cr}^{2+}$-doped II-VI materials, such as $\mathrm{Cr}: \mathrm{ZnSe}$ and $\mathrm{Cr}: \mathrm{ZnS}$, which have been critical to the development of a tunable, diodepumped mid-infrared laser. This novel class of $\mathrm{Cr}^{2+}$ lasers exhibit good efficiency and broad tunability in the 2 to $3 \mu \mathrm{m}$ range when pumped with long-wavelength $1.65-1.8 \mu \mathrm{m}$ InGaAsP laser diodes. ${ }^{3}$ The production of highly-doped, low optical loss Cr:ZnSe and Cr:ZnS crystals to improve laser performance has been the focus of the materials part of the project. Optical losses tend to be $10-20 \% / \mathrm{cm}$ which significantly reduces laser efficiency.

There are three growth techniques available that have produced samples that lase: the Bridgman method, Seeded Physical Vapor Transport (SPVT), ${ }^{4}$ and diffusion doping. ${ }^{5}$ SPVT material appears to provide the best optical quality and lowest losses to date, but doping to high $\mathrm{Cr}^{2+}$ concentrations is not straightforward. Bridgman grown crystals tend to have large parasitic losses due to inclusions and/or voids which have been reported to be attributed to selenium-rich or metal-rich precipitates. ${ }^{6}$ Diffusion-doping, however, appears to be promising since both single crystal and fine-grained polycrystalline window material can be used; window material provides a unique opportunity since it can be obtained in very large size pieces with low impurity levels.

We have concentrated on diffusion doping which is a relatively simple solid-state technique to diffuse $\mathrm{Cr}$ vapor into crystals. The process entails sealing a $\mathrm{ZnSe}$ or $\mathrm{ZnS}$ crystal into an evacuated quartz ampoule with $\mathrm{CrSe}$ powder. This ampoule is then heated in an isothermal furnace at a temperature that sublimes the $\mathrm{CrSe}$, creating a $\mathrm{Cr}$ atmosphere around the $\mathrm{ZnSe}$ crystal (Figure 3 ). By adjusting the diffusion time and temperature, control can be maintained over the $\mathrm{Cr}$ concentration achieved in the crystal. This process has generated approximately $3 \mathrm{x}$ higher doping in crystals than has been previously achieved by the Bridgman or SPVT methods. However, one complication that arises is that diffusion occurs at temperatures high enough to cause selective evaporation of the host crystal thus altering the stoichiometry so that production of defects is likely. By incorporating excess $\mathrm{Zn}$ vapor into the 
diffusion ampoule to counteract evaporation from the crystal, we have been able to reduce the optical losses by over $50 \%$.

The progress achieved to date on improving the optical quality and increasing the doping concentration of $\mathrm{Cr}$ in both $\mathrm{ZnSe}$ and $\mathrm{ZnS}$ has made a significant impact on the performance of the laser. Efficiencies are expected to increase further as this project continues and higher quality crystals are achieved as well as optimization of the laser geometry.

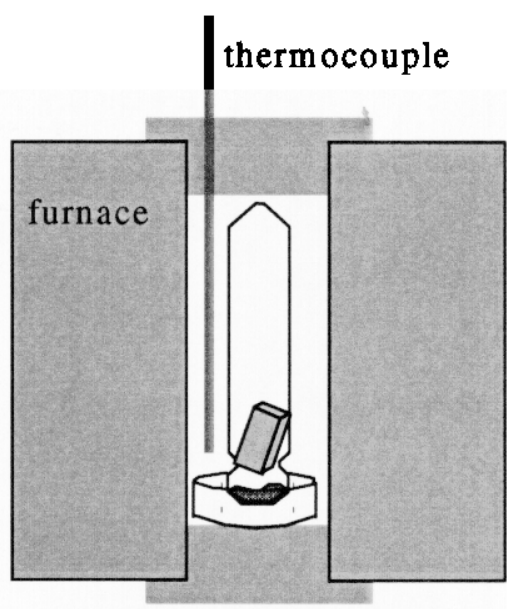

Figure 3

During FY96, we have studied and grown crystals of $\mathrm{Yb}: \mathrm{S}-\mathrm{FAP}, \mathrm{Yb}: \mathrm{Sr}_{5-\mathrm{x}} \mathrm{Ba}_{\mathbf{x}}\left(\mathrm{PO}_{4}\right)_{3} \mathrm{~F}$, La:S-FAP, and $\mathrm{Cr}^{2+}: \mathrm{ZnSe}$, for use as the gain media for diode-pumped solid-state laser architectures. The cloudiness in as-grown boules of Yb:S-FAP has been alleviated by a postgrowth annealing process and the investigation of the core defects have led to a better understanding of their origin and possible methods of reducing or eliminating them to improve the quality of the crystals. By adding Ba to the $\mathrm{Yb}: \mathrm{S}-\mathrm{FAP}$ lattice $\left[\mathrm{Yb}: \mathrm{Sr}_{5-\mathrm{x}} \mathrm{Ba}_{\mathbf{x}}\left(\mathrm{PO}_{4}\right)_{3} \mathrm{~F}\right]$ we have effectively increased the absorption linewidth to better accommodate diode-array pump performance. Finally, diffusion doping of $\mathrm{Cr}$ into $\mathrm{ZnSe}$ and $\mathrm{ZnSe}$ host materials has proven a useful method for increasing the doping concentration and the addition of $\mathrm{Zn}$ into the process has led to $\sim 50 \%$ lower losses in the crystals.

\section{References}

1. "Taking Lasers beyond the National Ignition Facility," Science \& Technology Review, Lawrence Livermore National Laboratory, September 1996, pg. 4.

2. K. I. Schaffers, A. J. Bayramian, C. D. Marshall, J. B. Tassano, and S. A. Payne, "Analysis of $\mathrm{Sr}_{5-\mathrm{x}} \mathrm{Ba}_{\mathrm{x}}\left(\mathrm{PO}_{4}\right)_{3} \mathrm{~F}: \mathrm{Yb}^{3+}$ crystals for improved laser performance and diode pumping," presented at Advanced Solid State Laser Conference, Orlando, FL, 27-29 January, 1997.

3. R. H. Page, K. I. Schaffers, L. D. DeLoach, G. D. Wilke, F. D. Patel, J. B. Tassano, S. A. Payne, and W. F. Krupke, " $\mathrm{Cr}^{2+}$-doped zinc chalcogenides as efficient, widely-tunable midinfrared lasers," in press. 
4. G. Cantwell, W. C. Harsch, H. L. Cotal, B. G. Markey, S. W. S. McKeever, and J. E. Thomas, "Growth and characterization of substrate-quality ZnSe single crystals using seeded physical vapor transport," J. Appl. Phys. 71, 2931 (1992).

5. K.-T. Chen, T. D. Journigan, S. Lecointe, J. Tong, A. Burger, L. D. DeLoach, K, I. Schaffers, R. H. Page, and S. A. Payne, "Diffusion of chromium and its solubility in zinc selenide crystals for $\mathrm{Cr}+2: \mathrm{ZnSe}$ tunable laser applications," presented at the Sixth Eastern Regional Conference on Crystal Growth, Atlantic City, NJ, 15-18 October 1995.

6. K.-T. Chen, M. A. George, Y. Zhang, A. Burger, C.-H. Su, Y.-G. Sha, D. C. Gillies, and S. L. Lehoczky, "Selenium precipitation in ZnSe crystals grown by physical vapor transport, " $J$. Crys. Growth 147, 292 (1995). 


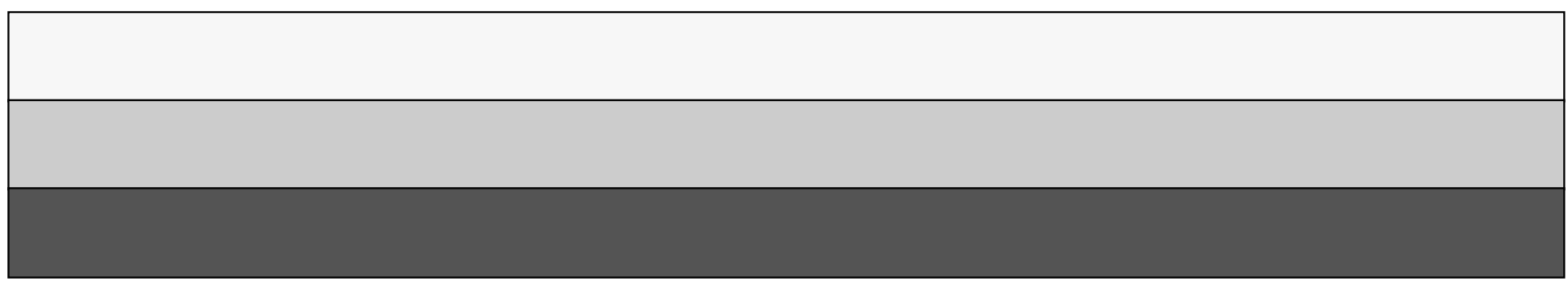

